\title{
Learning Local Immigration History In and Out of the Museum
}

\author{
*Jeremy Stoddard, ${ }^{* *}$ Alan Marcus, ${ }^{* * *}$ Kurt Squire, ${ }^{* * * *}$ John Martin
}

\begin{abstract}
In this article we utilize three case studies from the US as models for structuring historical inquiry in museum education programs focused on local immigration history. We focus on how models of practice from museums can be utilized as part of authentic history education pedagogy - in particular conducting historical inquiry with archival material and creating engaging exhibits. The three cases we draw from are the Tenement Museum (New York City), the Open House exhibit at the Minnesota History Center (St Paul, Minnesota), and a middle grades project in the Greenbush neighborhood (Madison, Wisconsin).
\end{abstract}

Key Words: Museum Education, History Education, Immigration, Inquiry, Mobile Learning

\section{Introduction}

It is a common middle grades history assignment for students in the US to explore their family genealogy in order to learn about their ethnic, immigrant, or migrant history. This kind of exploration often leads to discussions with family members about their ancestors and an opportunity for the teacher to help students connect their family experiences with the history they are learning. Questions may be raised about why ancestors or groups emigrated, why they decided to settle in particular regions, or what other push/pull factors drove their movements.

However, given the patterns of migration and now gentrification in American cities and regions, this personally important inquiry into students' own ethnic and migrant or immigrant pasts does not necessarily help them understand the history of peoples who have lived in their local area or region. For example, it will not help them to understand which American Indian peoples may have lived in their region in the not so distant past. Nor might this exploration identify rich immigrant histories from previous decades, as patterns of immigration in the United States have shifted from Anglo to Northern European, to Southern and Eastern European (or Asian in the Western US), to more recent immigrant groups from South Asia, the Middle East, and sub-Saharan Africa or members of the African Diaspora. Similarly, in other countries where there is an influx of new immigrants or refugees, there are bound to be tensions that emerge. Using public and school based history education programs can be helpful to engage these tensions through learning about immigration history and persistent issues. Through the study of immigration, and particularly inquiry into immigrant groups' perspectives, and the politics and contexts surrounding immigration, elementary or secondary students may be able to better gain a sense of their role as global citizens and identities as members of local, national, and international communities (Banks 2008: 131-37).

In this article we explore three cases of historical inquiry related to local immigrant histories presented in and out of museums. We then use these cases of museum, archival, and augmented reality work as a model for designing museum education programs that also meet the needs of history educators focused on interpretive fieldwork with their students. In doing so we utilize theories and models of practice from museum studies, history education, and new digital media focused on mobile technologies and augmented reality environments. We use these models to argue for a museum and public history approach to promote museum education programs that provide authentic historical inquiry into the traces of immigrant pasts in local communities and the ways in which immigrant heritage is constructed. 


\section{Museums as Sites for History Education}

Museums afford the chance to learn about history in ways not available elsewhere. They break the cycle of textbook and lecture-oriented instruction that focuses on memorization of facts, and instead create access to deeper historical understanding. Museums also provide a medium and site for engaging in the types of 'best practices' history pedagogy favored by history educators and many state standards. The goals of this pedagogy include improving students' ability to: 1) analyze, synthesize, and evaluate historical evidence (Wineburg 2001), 2) increase historical empathy - particularly to recognize the perspectives of others (Barton and Levstik 2004: 208-23), 3) examine and interrogate historical narratives (Barton and Levstik 2004: 129-46), 4) know, practice, and advance other historical thinking skills such as asking questions, understanding cause and effect, and determining historical agency (Seixas 1996: 765-83), 5) make connections between the past and today (Seixas 1996: 765-83), 6) recognize and account for presentism (viewing and judging the past through contemporary values and beliefs) (Wineburg 2001: 90), and 7) participate in dialogue and decisions about controversial issues that may challenge nationalistic historical meta-narratives (Barton and Levstik 2004: 167-80; Hess 2009). Museums support these facets of historical understanding through the physical space they design, the artifacts they preserve and present, the expertise of professional staff, and the special programs and online resources they offer. For example, The Mark Twain Home in Hartford, CT, promotes the discussion of the controversy over slavery, while the Shoah Museum in Paris, France, provides incredible opportunities for the development of historical empathy through powerful images and artifacts of the Holocaust.

Museums are also sites for connecting with persistent historical issues that are still relevant today, and engaging in historiographical analysis of how the past is represented over time. Many museums present exhibits about contemporary issues that are specifically linked to historical issues, including content examined in other exhibits. For instance, the United States Holocaust Memorial Museum contains a permanent exhibit on modern genocide (e.g. Sudan) with explicit links to the Holocaust. These past-present connections are not just about attracting visitors, but, as is the case at the USHMM, they often speak to the core mission of the museum. This is why issues like immigration are meaningful as the center of a museum education program, given the timeliness and prevalence of immigration around the globe.

Some museums, particularly living-history museums and historic houses, present the past in a way that is recognizable today. They often focus on typical lifestyle issues such as growing and preparing food, leisure and entertainment, education, occupations, relationships, and environmental/human threats (e.g., Ellis 2002; Reid 2002). Students today bring a different lens to these issues, but easily recognize their relevance to today. For example, the National Holocaust Centre in England provides visitors with a 'Journey' telling the fictional story of a German-Jewish boy through a serious of rooms including a 1930s home, a school house, and a German street.

Falk and Dierking report that many people identify museums as 'reliable, authentic, and comprehensible' (2000: 2). Museums are also viewed as very trustworthy sources of historic information - more trustworthy sources than college history professors, high school teachers, and nonfiction books (Rosenzweig 2000: 91). However, museums act like any other source of historical knowledge. The story of the past they tell is influenced by many factors, including subjective decisions by museum staff, financial considerations, and external social and political pressures. As a result, students, teachers and the general public often perceive museums as reliable, authoritative, and authentic.

Given this view of museums as historical sources, we are highly conscious that museums, often the first large institutions that students encounter outside the classroom, play a powerful role in shaping students' conceptions of their possibilities as civic actors and help frame their views of the role that cultural institutions can play in their own lives. As such, the formal and informal educational experiences young people receive at museums do double duty as both sites of learning and as potential sites for encouraging active citizenship. Here, we argue that engaging students actively in the history of immigration may help them to examine the perspectives of those immigrants, as well as the policies and contexts of immigration. This inquiry into the immigrant experience provides opportunities to both gain knowledge and perspectives, to understand the legacy of policies of assimilation, and the conditions of 
immigrants past and present. As Banks (2008) notes, the practice of assimilation as a liberal policy for national citizenship is out of date and ineffective given rising levels of immigration and diverse populations across the world,

Global immigration and the increasing diversity in nation-states throughout the world challenge liberal assimilationist conceptions of citizenship. They raise complex and divisive questions about how nation-states can deal effectively with the problem of constructing civic communities that reflect and incorporate the diversity of citizens and yet have an overarching set of shared values, ideals, and goals to which all of the citizens of a nation-state are committed (Banks 2008: 130).

A museum inquiry approach provides a framework for authentic learning and the context for students to begin to develop the knowledge, beliefs, and dispositions necessary for democratic citizenship. Of course, authenticity is a contested and limited concept when applied to learning, as no experience can be purely authentic. Shaffer and Resnick identify four kinds of authentic learning: 1) learning that is personally meaningful, 2) learning that relates to the outside world, 3 ) learning that is modeled after disciplinary practices, and 4) learning where assessment reflects the learning processes (1999: 195).

In order to structure authentic learning toward these goals, teachers need to involve students in activities during the visit that engage them in recognizing the stories and perspectives that exist in the museum, while also encouraging them to ask questions about the interpretation of these objects and stories. Museums provide a perfect site for students to develop not only historical thinking skills that ask them to analyze and reflect upon issues of purpose, interpretation, significance, authenticity, but also to hone skills in visual and critical literacy. They can also be engaged in developing public presentations of their inquiry work, which Barton and Levstik refer to as an 'exhibition stance' on history (2004: 110). They argue for students to be engaged in creating public exhibitions, while also promoting a more critical stance towards the past in order to challenge nationalistic or ethnocentric historical narratives (114).

The demystification of museums does not make them less useful to visit, but instead bestows a wonderful opportunity for students to explore how museums present a subjective and selective past and how history is 'made.' Students can learn that all history is an interpretation of past events and people, and is laced with subjectivity, interpretation, hypotheses, and particular narratives (Hooper-Greenhill 2000: 1-10). Museums are public spaces of historical narratives that are shaped by society while also influencing society. Museums help students develop ideas, beliefs, and attitudes about public spaces (Nespor 2000), and about their own rights and ability to enter into civic engagement. They also provide an opportunity to escape the 'corporate multiculturalism' of the classroom (Ladson-Billings 2003a: 53) that often leaves immigrant perspectives in the margins (Ladson-Billings 2003b; Loewen 1995: 170-77), and instead focus on inquiry into, and the challenging of, these kinds of meta-narratives in history. This approach to examining the history of immigration will also help students examine the tension between subsequent immigrant groups as they compete for economic, social, and political capital (Ladson-Billings 2003a).

Museums as Sites for Authentic Historical Inquiry

Authentic pedagogy, authentic assessment, and authentic teaching are terms that are used frequently in education but which often reflect a wide range of meaning and conception. For history education, authenticity may mean engaging with intellectual work that has relevance to the world outside of school (e.g., Newmann 1991:412-13); it may mean pedagogy structured on the academic discipline of history and the work of historians (e.g., Wineburg 2001; VanSledright 2011); or, it might mean engaging in identifying and exploring problems that are historically important for working toward the common good (e.g., Barton and Levstik 2004: 25-40). For us, authenticity involves facets of engaging in authentic problems and questions, modeling inquiry on the work of professionals, and producing knowledge communicated for authentic audiences. We do not believe in students constructing warranted historical accounts for the purpose of a teacher's evaluation and grade. We want students engaging in thoughtful inquiry that is then presented and communicated for external audiences using new media - or better yet - producing designed experiences for external audiences to engage in actively themselves (Squire 2006; Squire et al. 2007). 
As noted above, museums offer wonderful opportunities for students to engage in inquiry activities to help them understand the past. Museums inspire students to ask questions, provide historical sources and evidence to be evaluated, present opportunities to explore content and disciplinary concepts, and encourage students to be involved in the community. The resources and context of museums enable teachers to promote a sophisticated understanding of the past and the development of habits of mind in ways that are not easily duplicated in the classroom. Their physical space, artifacts, professional staff, special programs, online resources, and other features create opportunities for students to deepen understanding of specific content and to develop historical thinking and critical literacy skills, particularly the skills and practices of inquiry. These resources and experiences provided at museums can complement the school curriculum (Lenoir and Laforest 1986) and make studying history more vivid, engaging, and relevant. Leaving the school to visit a museum can allow students to engage with a combination of artifacts, ambience, narratives, and other recreations of the past, as well as the geography of historic sites. Museum education programs also have the potential to promote critical literacy of visual representations of the past, such as helping students navigate the visual culture and power relations illustrated in museum spaces (Hooper-Greenhill 2000: 16-20).

In addition, for our purposes here, students may be more inspired to think critically about primary sources or larger interpretations of history when they are confronted by both in museums. Museums also create the potential to interrogate historical interpretations by looking critically at how individual museums choose to present and interpret the past - what narratives they construct about our past and tell us about the present. Few other disciplines have such a readily available and rich set of resources designed to support student learning as well as the staff to collaborate with teachers to formulate these learning experiences. However, the potential contribution of museums to the history education of students is largely dependent on the practices of teachers and museum staff (Marcus, Stoddard, and Woodward 2011: 5).

Museums offer the potential to support authentic inquiry pedagogy, and the more critical and place-based pedagogies that are now at the forefront of history education. Over the past three decades, there has been a movement in history and social studies education to help students develop historical inquiry skills and the ability to engage with different types of historical evidence. This movement came in part from the evolution of constructivist teaching practices of the 1960s and 70s, but also from the push for more authentic forms of pedagogy that emulate disciplinary forms of thinking. Museums provide opportunities for inquiry through engaging students in real world explorations of the past from the perspectives of historians, archaeologists, anthropologists, curators, and other staff. Similarly, the past three decades have seen major growth in new museums or museum exhibits focused on the histories and cultures of historically marginalized groups. In particular, museums such as the Smithsonian National Museum of the American Indian and the Wright Museum of African American History have begun to tell the stories of groups who have been marginalized in the dominant national story of the United States. Similarly, museums in Europe such as NiNsee (Nationaal Instituut Nederlands slavernijverleden en erfenis), the Dutch museum, have emerged to help their citizens explore their role as a nation in the history and legacy of the trans-Atlantic slave trade.

Another example of this kind of new museum, the Lower East Side Tenement Museum in New York, provides the opportunity for visitors to explore the history of urban immigration through the rooms of an actual tenement. This museum was established by a group of people to 'give voice and presence to peoples, pasts, and places forgotten in national narratives... [as an] alternative place of memory' (Till 2003: 296). The tours at the Tenement Museum tell the stories of the generations of immigrants who lived there, and also provide insights into the historical and archival processes that led to the discovery of the building and the presentation of artifacts in the exhibit rooms. This experience inside of the tenement is now being expanded to walking tours - including food-themed neighborhood tours to engage visitors in examining and learning about the impact of restaurants and food in the local area - and how this heritage exists or is constructed still today (Steinberg 2012). Of course, this kind of memory-as-tourism can lead to further stereotyping of the immigrant experience (Conforti 1996), unless these programs invite visitors to reflect on these histories and challenge dominant narratives about immigrant groups and the challenges and controversies in the immigrant experience. This represents the complicated line between heritage and history. It also represents the difference 
between a 'heroes and holidays' or ' contributions'1 approach to multiculturalism versus a more critical approach that asks visitors to engage with the hardships faced by immigrant groups historically and today, and the tensions between immigrant groups and largely White middleand upper- class citizens (Banks 2008; Banks and Banks 2009: 237; Ladson-Billings 2003a).

It is this kind of work that we hope museum education programs, in conjunction with schools and other informal education groups, can replicate in the form of authentic pedagogy. This kind of authentic historical inquiry, modeled on the work of museum studies, would include: 1) a focus on an authentic historical question related to inquiry into the history of a group, individual, movement, or event; 2) the use of archival data, oral histories, and artifacts or material culture objects to construct a historical account; 3 ) the analysis and contextualization of this evidence within the context of the period and place of the history, as well as within the historical record; and 4) the presentation of this evidence and narrative through the curating of an exhibit or designed experience for authentic audiences that helps them engage in both the history, and the processes used to inquire into this history. Essentially, like the Tenement Museum tour, we want students to be able conduct historical inquiry and construct an exhibit or experience based on this inquiry, as well as reflect on the choices they make in creating this exhibit, including the narrative they construct or questions they want to raise for visitors. This model of inquiry combines the best of historical inquiry from the world of history education with the work of museum staff in researching and constructing engaging exhibits for their viewers that tell stories in a way that also provides some transparency for visitors into the constructed nature of this exhibit or experience (Marcus, Levine and Grenier 2012).

\section{Authenticity, Museum, and Place-Based Learning with Mobile Technology}

One of the most exciting innovations within museum education in the past decade is the use of mobile and augmented reality technologies to engage visitors. Museums are exploring ways to utilize mobile technologies for everything, from using QR codes to help visitors access additional information about particular objects and exhibits, to using augmented reality apps like ARIS to design museum-based games to engage young visitors in a designed museum experience ${ }^{2}$. ARIS is an open source platform for creating and playing mobile games, tours, and interactive stories. ARIS, like other mobile gaming platforms (e.g., TaleBlazer, FreshAir, Aurasma), is designed for formal and informal educators and students to construct place-based games, simulations, and experiences. ${ }^{3}$

These platforms are designed to be user friendly and allow flexibility. They have been used for inquiry-based learning in everything from local ecosystems to exploring the history of local events (e.g., Matthews and Squire 2009; Squire 2010). At the heart of the mobile augmented reality experience is the ability to engage an authentic inquiry problem in a local space, be it a neighborhood or an ecosystem, using both the surroundings and the ability to access data and sources of information via a mobile device. Additionally, mobile augmented platforms give students the ability to capture data and information for use in attempting to come up with answers or explanations to the inquiry problem. In museums such as the Minnesota History Center, ${ }^{4}$ mobile games help visitors to engage with interactive museum exhibits. For the students who created Greenbush ${ }^{5}$, described below, the task was to research and design an ARIS-based game as an inquiry experience for other students and adults to undertake. Similarly, Gottlieb has designed an augmented reality experience to help visitors to New York experience moments in the history of its Jewish residents (2014). These are just two ways in which museum education programs may make use of new mobile learning technologies and media platforms to engage people young and old in their mission, stories, and exhibits.

So far, we have attempted to outline what we see as an opportunity for museum education programs to engage visitors, and particularly student visitors, in authentic inquiry as part of their museum experience. Below we use three case studies to focus on models of authentic inquiry focused on local immigration history and illustrating a museum studies approach to research and design. We then use these case studies to outline a model we propose for museum education, grounded in situated learning and focused on authentic inquiry into local immigration history based on place-based research and designed experiences for students. 
Atheory of situated learning presumes that learning takes place in social and collaborative environments. From this perspective, thinking and learning in museums is not limited to an individual interacting with objects but is also influenced through interactions with others within the particular physical and cultural environment (Brown Collins and Duguid 1989; Chaiklin and Lave 1993). These learners are also influenced in their experiences with museum exhibits and objects by their past experiences, cultural narratives of history, and other 'cultural tools' (Wertsch 1998). Each of these three model sites offer aspects of augmented reality designed to provide authentic experiences to visitors through providing opportunities to empathize with immigrant and ethnic minority groups within particular historical contexts. Technologies that foster augmented reality and the ability to engage in place-based learning using mobile devices also reflect this theory of situated learning.

\section{Case Studies of Inquiry into Local Immigration History}

As mentioned above, one of the trends in museums and museum education over the past decades has been an emphasis on the history and voices of those who are often marginalized. This movement aligns with the emphasis on social history among professional historians and the multicultural education movement within schools. We use three specific US cases of local immigration history exhibits below to illustrate the types of inquiry and museum approach to these histories and voices of immigrants that also reflect the model for authentic inquiry pedagogy we are proposing. The first two museum sites are presented as cases of public pedagogy (Trofanenko 2006: 309-11) and as models for doing museum-based inquiry into local immigration history. The third case is an example of how students may be engaged in this kind of museum-based inquiry as well as a case of place-based learning where the 'museum' takes the form of an on site augmented reality experience.

The descriptions below are based on our observations and research at these sites, unless otherwise stated. These cases are the Lower East Side Tenement Museum, located in Manhattan (New York), the Open House exhibit at the Minnesota History Center (St Paul, Minnesota), and the Greenbush Neighborhood augmented reality project from Madison (Wisconsin). These exhibits also represent sites of situated learning, and our description and use of these case studies reflects this theoretical perspective of the museum experience as a social and collaborative learning experience for visitors. These exhibits provide opportunities to engage with the past through material culture objects, the stories and oral histories of immigrants, and 'designed experiences' augmented by mobile devices within historic spaces.

Lower East Side Tenement Museum (New York City): The establishment of the Lower East Side Tenement Museum in Manhattan was based partly upon luck and partly upon stalwart determination. As told on the museum's website, the founders of the museum had all but given up hope of finding a site for a museum focused on American immigrants who had inhabited New York City. They then came across the largely closed up building at 97 Orchard Street on the Lower East Side. This building, which had housed generations of immigrant families, was deemed uninhabitable by the mid-1900s and was left largely in its original state when the founders of the museum discovered the space. Over the past 20 years, they have painstakingly recreated the living quarters to reflect the various time periods and ethnic groups who would have occupied the building. The Tenement Museum's main exhibit consists of six refurbished apartments in the tenement that present the history of the families that once lived there, and the progression of immigrant groups during the nineteenth and twentieth centuries. The total number of people who lived in the tenement between 1863 and 1935 is estimated to be $7000 .^{6}$

The Tenement Museum's design serves as a model for inquiry into local immigration history. In order to recreate the six apartments, which each reflect a particular family's experience of living at the tenement, many decisions had to be made and evidence collected from a variety of sources. These spaces tell the story of individual families but also reflect the changing nature of life in the tenements, the changes in construction, technology, and use of space, and the shifting immigrant groups who resided in the Lower East Side. Of course, while the family names and stories at 97 Orchard are based on the historical record, much of the exhibition reflects the general material culture, possessions, and experiences of the ethnic groups they represent and their experiences in New York during the time being portrayed. 
The Tenement Museum has compiled a list of 'alumni' who lived in the building, based on a variety of records, including the property owner's documents, census records, birth certificates, and voting and other court records. These records provided a starting point for discovering as much as possible about the families who resided at 97 Orchard and gave the staff a pool to select from as they expanded their exhibition to reflect the major shifts in people and space over a century. In order to design the exhibition spaces, they used photographs from family archives and even crime-scene photographs from similar tenement dwellings. This research on tenement life in New York and the archival data, photographs, and material culture archives and exhibits were then used to design and develop the six apartment exhibits that tell the stories of the families and ethnic groups they represent.

The Tenement Museum uses the physical space of the tenement as the canvas for a designed visitor experience. This experience, which is only available as a guided tour as a result of the building condition, leads visitors through time as they go from apartment to apartment. Starting with the street-level shop, once a saloon run by the German Schneider family, visitors to the museum work their way up flights of steps, and move chronologically backwards and then slowly forward in time. Visitors experience the culture and histories of the families while also experiencing the increasingly dense and decrepit accommodations in the tenement - with more and more people living in smaller spaces as time progresses. The stories reflect the highlights and challenges immigrants faced during the time, from the German-Jewish Gumpertz family to the Italian Baldizzi family or the Irish Moore family, all of whom lived in one of the cramped apartments at 97 Orchard during the nineteenth or early twentieth century. This physical engagement with the space of the museum, in addition to the material culture and stories of the inhabitants, provides opportunities to recognize the day-today experiences of New York immigrant families.

The narrative of the experience is constructed as a result of the material of the apartments, the physical space of the tenement, and the stories told by the tour guides. The voices of the immigrant residents of the tenement are therefore transmitted through the staff and interpretation of the Tenement Museum, but visitors are also given the opportunity to develop empathy for the lived experiences of these tenants through seeing the spaces they lived in and the material artifacts that would have likely been part of their lives. Given the tight space visitors wander through, the tour itself provides an aspect of an augmented reality experience of the cramped tenement quarters. The tour and visit also highlights the reconstructed nature of the museum and the history of its (re)creation. This visitor experience is the result of the luck of finding a space largely unchanged at 97 Orchard, the inquiry into the former residents of the building, and the designed experience of the Tenement Museum curators and staff to help visitors engage physically with the tenement as they walk through the dimly lit corridors and windowless back room apartments. In this way, the physical space blends with the represented pasts of immigrants' stories and lives, and provides opportunities to reflect on these representations and the identities, perspectives, and histories of those represented. This reflective component in all of these museum-based experiences is key to helping students recognize the limits to authenticity and augmented reality; in particular their own limits to fully understand the perspectives and experiences represented in the exhibit and the decisions of the exhibit designers (Hooper-Greenhill 2000).

Minnesota History Center "Open House" Exhibit (St Paul, MN): 1200 miles away from the Lower East Side of Manhattan, an exhibit at the Minnesota History Center ${ }^{7}$ takes a different approach to giving voice to its many historical immigrant groups. Although most people in the United States would not think of Minnesota as a home of immigrants past the Scandinavian settlers of the mid-to-late nineteenth century, the twin cities area of Minneapolis and St Paul in particular has a rich immigrant past. In addition to the Indigenous peoples who once populated the area, waves of immigrants have crossed the Mississippi River to move into St Paul over the past three centuries. The first Europeans included French fur trappers and traders, primarily in the eighteenth century. The French were followed by other European groups who emigrated primarily in the nineteenth century, including Irish, German, and Scandinavian immigrants.

However, the story of immigrants continues in the Twin Cities area throughout the twentieth century and into the present. These immigrant groups came for different reasons 
than previous groups; most were refugees or migrants, and include African-Americans during the Great Migration period, Hmong, Laotian, other South East Asian people who arrived during and after the Vietnam War era, and, more recently, Somali and other East African immigrants who started to arrive in the 1990s.

The Minnesota History Center, which serves as the state history museum and functions under the Minnesota Historical Society, designed an exhibit to attempt to illustrate Minnesota's rich immigrant past while also providing personal histories and voices of some of these immigrants. Their exhibit, Open House: If These Walls Could Talk, is their attempt to teach about the broader immigration patterns of the area. Similar to the Tenement Museum, each room in the exhibit 'house' represents a different family and period of immigration. The effect in part is to connect immigrant groups often associated with Minnesota, largely from Northern Europe, with newer immigrant groups and immigrant experiences, such as those of refugees from Southeast Asia. This exhibit was recreated inside of the museum, but is based on the residents of an actual house located at 470 Hopkins Street on the east side of St Paul.

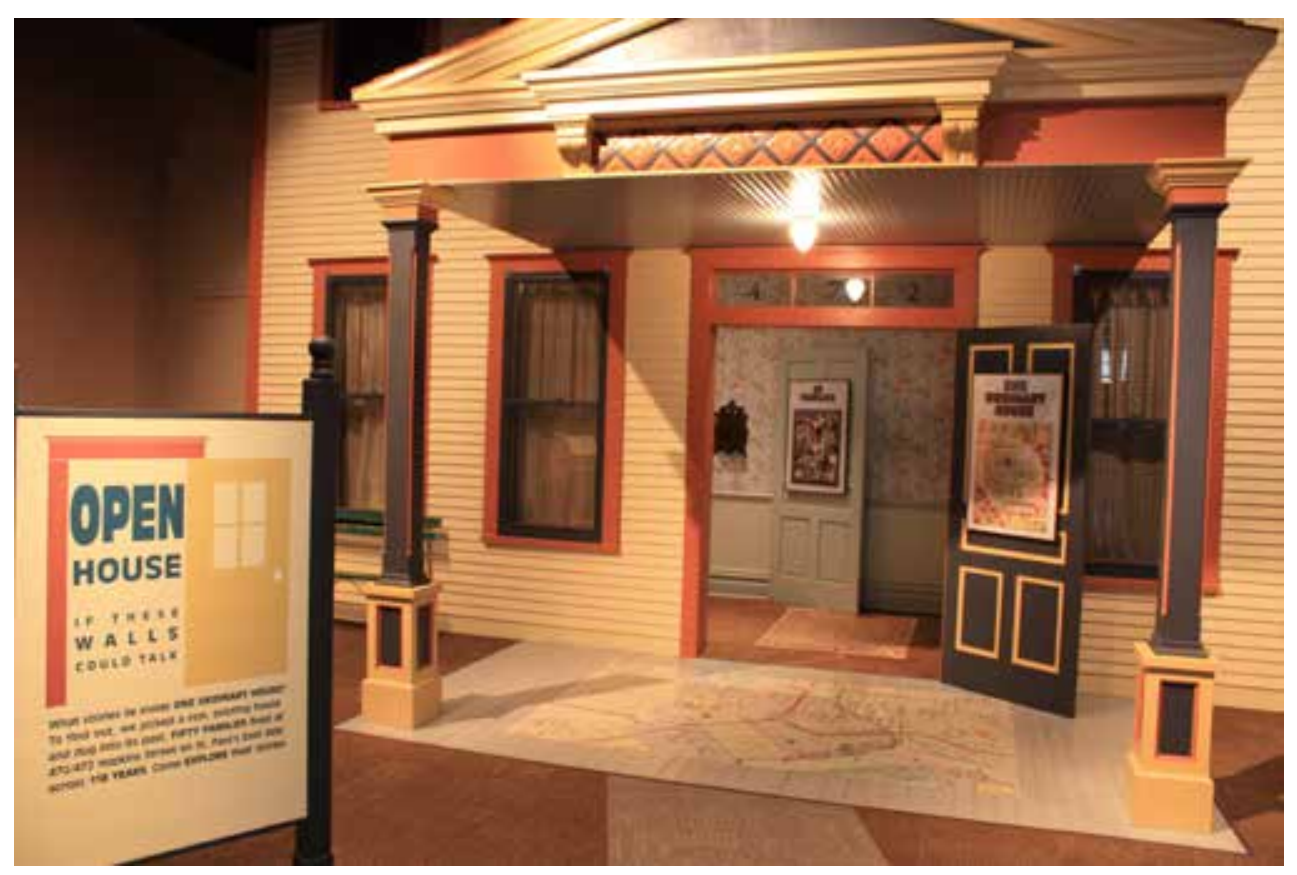

Fig 1. The entrance to the Minnesota History Center's If Walls Could Talk Exhibit. Used with permission of the Minnesota Historical Society

Unlike the Tenement Museum's apartments, which have been unoccupied since before World War II, the house on Hopkins Street has had continuous occupants from early German settlers to Italian, African-American, and Hmong families. As a result of this continuous occupancy, and the records from census and land record archives, the exhibit designers and researchers were able to collect not only representative artifacts from the periods, but also the voices of a number of the occupants or relatives of the occupants. This oral history research led to a collection of stories from the occupant families, adding a layer of depth to the exhibit missing from the Tenement Museum. Given the role of the Minnesota History Center as the museum for the Minnesota Historical Society, the exhibit also reflects the rich body of historic archives and professional research staff that worked on the exhibit. In this way, the exhibit functions for visitors to learn about the perspectives of those who are represented, as well as how the research and design of the exhibit was done. The online site provides insights to the exhibit 
itself as well as a 'tool shed' of resources for conducting historic house research (more on this below).

Although a visitor to the MN History Center does not experience the same affective response as standing in the house itself, the recreated spaces of the Open House exhibit are made rich with the stories of the occupants, including their own words and voices. The stories are priceless artifacts that are told through audio recordings, objects, and placards. For example, the basement plays prominently across immigrant groups - as a site for making wine during an Italian family's occupancy as well as a place for butchering chickens during the time when a Hmong family was in residence. In some rooms the visitor hears the audio recording of a family's story on a recorded audio loop. In others the story is told more traditionally through placards and artifacts - but each room captures a specific story from the family's time on Hopkins Street in addition to reflecting the larger cultural and familial material artifacts from the historical context of their residence in the house. For example, there are pictures of a Hmong family wedding being held in the backyard and a simulated broken bed in one of the rooms that coincides with a child's recorded story about what was happening when the bed collapsed.

Although these stories may not seem consequential individually, they are moments of the captured history of immigrant families that provide visitors an opportunity to recognize the voices and experiences of immigrant families and their transition to life in Minnesota (Marcus, Stoddard and Woodward 2011: 59-60). Similar to the Tenement Museum, the designers of the exhibit attempt to provide visitors with an understanding of how the exhibit was created and how they represent the stories of those who lived on Hopkins Street.

These first two cases of museum exhibits as sites of public pedagogy and models for inquiry focused on immigrant pasts illustrate key concepts relating to doing inquiry into local immigrant history. These cases inform the curriculum model presented below. These cases focus on the rich histories of individual buildings and neighborhoods, and how both act as sites for exploring immigrant histories. They also illustrate the techniques used for this kind of inquiry from a museum studies perspective: archival research in county and state records, oral history, and partnering with state or local ethnic or neighborhood historical groups. Finally, they present models for sharing the stories of immigrants, immigration, and the challenges of living in a new place through using immigrant residences - either the actual rooms and building or a recreated space - and material artifacts to help tell the stories that were unearthed in the inquiry. These visual stories, augmented in Open House with some oral history recordings, help visitors to begin to recognize the perspectives of local immigrants through their voices and experiences. This affective experience helps us better to recognize perspectives and relate to the voices of the immigrants, but also may lead visitors to believe that they fully understand the hardships and experiences of immigrants if they are not engaged in reflecting on the exhibit and their understanding of the narrative it constructs.

Greenbush Neighborhood History and Augmented Reality Project (Madison, WI): The first two exhibits above illustrate how museum professionals attempt to use their tools and frameworks to construct spaces that tell the stories of immigration, at least in their local areas, and attempt to include the voices of immigrants in this narrative. The third case study differs. It is not the work of professionals, but of middle-school students. Furthermore, it does not take place in a museum or building converted into a museum, but on the streets of a neighborhood with a strong immigrant past. Although many of the same research techniques are used, including archival research and oral histories, the 'exhibit' is a designed experience that the students created using an augmented reality (AR) platform designed for mobile technologies. In this way, the museum is the neighborhood and the narrative is constructed by the visitor using the augmented reality materials (e.g., images, records, oral histories) and story.

The GreenbushAR Game started as a class project in Madison, Wisconsin, and became the quest of a sixth grade boy who wanted to engage people in the story of the Greenbush neighborhood. The Greenbush neighborhood is a historically Italian and Jewish neighborhood in Madison that, similar to the exhibits described above, has gone through both physical changes over the years as part of 'urban renewal' development projects, and changes in demographics. The boy researched the neighborhood as part of his work at school, and decided to create a game that engages players in the experiences of a boy in the neighborhood as it was in 1959. At this time the neighborhood was in the midst of an urban re-development project that impacted 
many of its residents and its immigrant and ethnic identity. With the help of his teacher, and later on some ARIS project members from the University of Wisconsin-Madison, the student developed the Greenbush Game. This game places players in the role of the boy and helps them discover Greenbush's immigrant roots using archival photos, maps, and stories as they work their way physically through the neighborhood, see what is there today, and what the neighborhood looked like a half century ago.

\section{Greenbush Game}
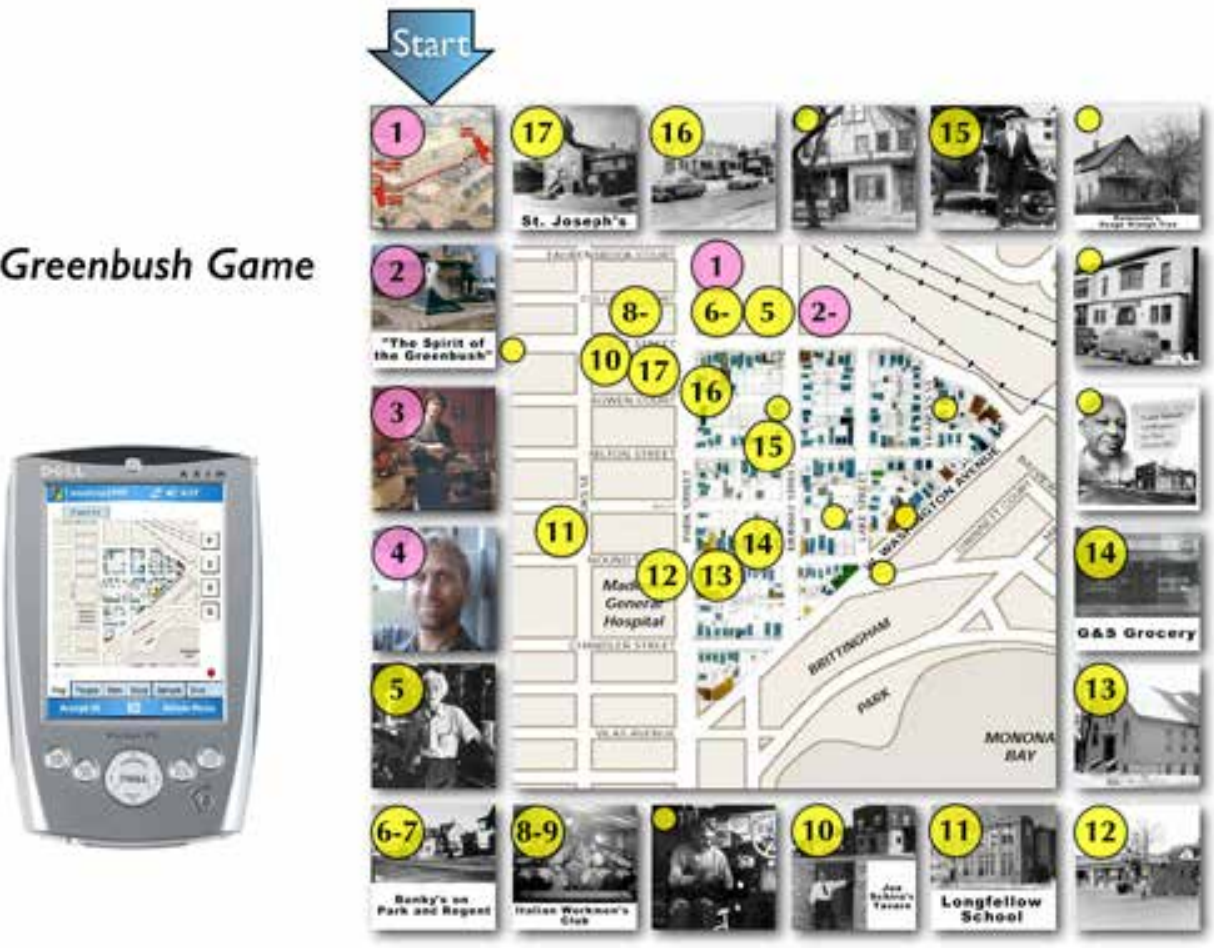

Fig 2. Participants hear stories, see historic (now razed) buildings, and meet previous Greenbush residents as they move through the game.

The game engages players through the issue at hand - the condemnation of properties and eminent domain procedures being used by developers. It introduces players to individuals and groups involved, including the still-present Italian Working Men's club, individual civic leaders, and historical characters through pictures of them, many of which appear in the geographical locations in which they were photographed. In addition to experiencing the history of the neighborhood and the events of 1959, the game also builds in civic engagement, as it illustrates what the citizens can do to help save their neighborhood and its ethnic identity. As part of the game, players are asked to go through the neighborhood to collect signatures on a petition to stop the condemnation of houses and other structures. Similar to the affective engagement in the Tenement Museum, where visitors walk into the cramped spaces of tenement apartments, in the Greenbush AR game, players are engaged in the spaces of the physical neighborhood - and both what is there and what is gone. This example shows the potential of mobile and augmented reality technologies as well as the power of student-driven inquiry and design. Furthermore, it illustrates another model for engaging in local history through museum education - but outside of the physical space of the museum. 


\section{Museum Studies Practices as a Model for Inquiry into Local Immigration History}

These three case studies illustrate the nature of research and design focused on local immigration history, and the presentation of this history through exhibits and designed experiences that exemplify 'best practice' models of authentic historical inquiry. They emphasize opportunities for the authenticity identified by Shaffer and Resnick (1999: 195). Each case focuses on local and compelling historical questions that have been largely overlooked or marginalized from both public and school history. Each project takes advantage of local sites, state and local government records and archives, and an examination of rich material culture and social history from exhibit design and oral history accounts. Finally, each project is designed to engage visitors or participants in these marginalized stories while also using affective elements of a designed experience that promotes empathetic understandings of immigrant experiences. They also all raise important issues about gentrification, migration, and the exploitation of immigrant groups - which lends itself to a civic engagement outcome as well.

How can these cases then serve as models for museum education programs? From the theoretical perspective of situated learning, we must consider how each site is designed to engage visitors or participants in collaborative learning opportunities within particular contexts. Our goal is also to consider here how students can be engaged in researching and designing historical experiences for others based on these principles. How can they help museums connect with educators, young people, and local immigrant groups to explore how immigrant groups have shaped their local history? Finally, how can these models be used to help young people engage authentically in the persistent issues faced by immigrant groups - including housing, exploitation, xenophobia, assimilation, and cultural and national identity? Through the remaining portion of this article we present a template for doing just these things. As every museum and local context is unique, and the histories and experiences of immigrant and migrant groups involved are different, we present a framework for museum education that is not intended to be prescriptive or comprehensive. However, we hope it represents a starting point for designing museum education programs that promote student engagement in the kinds of authentic inquiry done by museum professionals on the very timely and important topic of immigrant and migrant history and culture.

This kind of cooperative museum education program could be conducted at a museum site as part of a regular or intensive summer education program, in conjunction with local teachers and schools as an outreach activity, or through local community or cultural center groups as a way to engage new immigrant groups with the experiences of the immigrants who came before them. As the outcome of this project is a designed exhibit or experience for real audiences, it is also an opportunity for marginalized populations to share their voices and the voices of past immigrants with the larger community. This student-driven authentic inquiry and exhibition activity could be modeled on the three examples of museum and place-based historical exhibitions described above, and aligned with the framework of authenticity identified by Shaffer and Resnick (1999: 195).

1) Identifying local immigration issues and questions. One of the great resources of a museum is the expertise of the staff historians, archivists, and educators. This expertise can be used to engage students or young visitors in exploring the history of local immigration and help them to begin to identify potential interests, intriguing narratives and issues, and most importantly, areas in the historical record that appear to be missing or not inclusive of the history of immigrants' voices. For example, the Greenbush neighborhood was targeted for development in the 1950s and the expansion of institutions such as the local university and hospitals as well as ancillary businesses. The institutional historical records tell of a great time of development, investment, and prosperity in these anchor institutions - but often leave out the stories of those who were displaced and whose community was broken up as a result. Similarly, the history of New York City and its tenements is often one of despair, and of great relief when these tenement housing areas were developed and gentrified. What is often missing is accounts of the squalid conditions many new immigrants lived in and how they were exploited as cheap manufacturing labor or in other fields. In order to help young people engage in 
what history has been recorded, and to identify a problem, issue, or local building or neighborhood to research, they need to be exposed to secondary histories of immigrant groups, of the city or neighborhoods, and explore maps and census data reflecting the changing city and the shifting demographics of its residents along with the history of key events that may have caused these shifts.

A practical way to begin this kind of inquiry is to lead students around the neighborhood of interest. Have them point out historical markers, use their smartphones or cameras to photographic evidence of ethnic or immigrant histories, or to have them talk with some of the owners of businesses that have long served the neighborhood or other institutions such as churches or civic organizations. This kind of experience, especially if it is semi-structured to help them identify important landmarks, will help them identify questions about what they did not know about their neighborhood and the people who may have lived there - and engage them in formulating inquiry questions related to neighborhood structures or ethnic histories for further investigation (Ho and Seow 2013: 37-40). It is important, however, that this research is always placed into the context of the history of immigration in the area. These histories often include issues of power between immigrants and other residents or earlier ethnic groups, institutions, and labor and political organizations.

2) Finding local partners and archives. Once a problem or question has been identified, then students and staff can work together to identify likely sources for information and artifacts that will help them tell the stories of the immigrant experience. Depending on the issue, question, or particular space or place students want to explore, different partners may be of use. If students want to explore the history of a particular building or neighborhood, such as the examples above, starting points would likely include the local or state land records archive, a local historical society, and any kind of cultural or ethnic community group (e.g., Ancient Order of the Hibernians). As students begin to create maps and timelines of immigration patterns and important historical events, they can also work with museum archivists to identify documents or artifact archives that may be useful. This step in the process also provides an opportunity for museum education staff to help students learn how to best engage different groups and resources to enlist their help with the project. Professional communications should be emphasized as part of student work and research.

3) Researching the problem. Once the background history and contextual information is identified for the local area, building or issue they are exploring, participants can work in teams to identify all of the potential ways in which they can collect stories, data, and archival material to help piece together the story they are constructing. ${ }^{8}$ These sources may include: using oral history methods if living residents or former residents of the area are available; a full exploration of census and land records to analyze trends in migration patterns and to identify specific residents or their descendants; interviewing local cultural and historical groups; and learning how to research museum, library, and historical archives and databases. This work should be student-driven, but modeled on the work of museum staff and conducted with the assistance of museum staff members. Research skills should be emphasized, but the direction of the project should come from the students and the particular aspects of the history they find to be compelling or relevant.

This work can, of course, be extensive. If students are interested in a particular building, such as one that housed immigrant owned businesses over the course of decades and shifting groups, they could access numerous official documents, family and census records, and local historical accounts. For example, for a particular address or structure, they can use the following resources in their research: 
- City records, building and remodeling permits, business permits, tax or licensing records, and mortgage records could show owners or tenants.

- Police records could show any issues or tensions in the neighborhood involving the location or new immigrant groups.

- Maps could show the shifting development of the city, as well as more recent redevelopment or gentrification of these neighborhoods.

- Census records can reveal who lived in a particular location as well as their occupation, national origins and family structure.

- Local newspapers may have databases to search for photographs, announcements or city records postings, and advertisements from any businesses.

- Local libraries may have collections of letters or firsthand accounts of immigrants, or the reactions of other residents to the arrival and assimilation of new immigrant groups.

- Immigrant aid societies, such as the settlement houses in major urban centers in the US or Toynbee Hall in East London, are great resources for accessing immigrant histories.

- Identification of immigrant families and individuals from records may also be helpful in identifying the descendants of these immigrant residents who may be contacted in order to fill in some of the details of what the immigrant families or business owners experienced.

- Finally, elderly residents may tell stories of the businesses that were at that location during the time they lived there and what the role of the business was in the immigrant community - as well as tensions or issues that these immigrants faced.

In addition to helping students find this information, museum staff should help to structure this collection and analysis of the data and artifacts in a way that is systematic and helps them to begin to identify important themes and patterns.

Once they believe they have exhausted their collection of evidence and artifacts, students will need to work to construct narratives that address the problems or questions they are addressing. Students should begin by identifying the key periods or dates that they want to include in a chronology or timeline. They then need to identify the key voices or stories that best illustrate the history they are trying to communicate. Finally, they need to identify the most compelling artifacts that they have been able to acquire as well as artifacts that would be helpful in telling their story but may not be available.

4) The designed experience. Once students begin to piece together an immigrationrelated narrative, they need to begin to explore the best ways to engage others in what they have discovered. Below are several ways to construct these experiences. Some are more grounded in traditional museum presentation; others utilize new media to present the research for a broader audience outside of the museum and reflect new methods that many museums are exploring for their own collections and visitors. Regardless of the method of historical experience being designed, these should reflect the 'exhibition stance' described by Barton and Levstik (2004: 110-128) that emphasizes a more reflective model using public exhibitions to present historical inquiry from a socio-cultural perspective.

Students should be engaged in thinking about the best mediums for telling the story they have constructed. For example, what medium is best for engaging in the perspectives of the immigrant groups they have researched or interviewed? 
What is the best way to place these histories within the larger historical context? In the case of the Open House exhibit described above, curators incorporated audio recordings from their oral history research into the exhibit itself as artifacts to help illustrated the story and fully engage visitors. On the other hand, the Greenbush example shows how an augmented reality platform can be used with mobile technology to engage visitors in the history of immigrants and the local community while they walk the neighborhood. Each of these examples present particular affordances for the story they want to tell and the types of artifacts or objects they will use to construct the visitor experience.

Museum exhibit. If the education program takes place in the museum, students could take part in designing a small exhibit alongside museum education staff using the research they have done and artifacts they have identified. This exhibit could be used, for example, to focus on the experiences of immigrant children growing up in tenement housing or within a particular community. Likewise, it could focus on the evolving experiences of children from subsequent immigrant groups: from the experiences of immigrants in the nineteenth or twentieth century to those of present day immigrants or refugees.

School or community-based exhibits. If the goal is to help engage students in developing a better understanding and a stronger relationship with more recent immigrant communities, the exhibit could be designed for a school or community center. Students could incorporate images, artifacts, and media to present the history of immigration in the neighborhood or a topic focused on a local issue such as immigrant labor issues or housing. This could be a traditional static exhibit designed for a front hallway or library display case, or a more dynamic exhibit that invites students to contribute their own experiences and understandings of local history and local immigrant history. The exhibit could also be used as a call for civic action to preserve the local history of immigrants, or to establish historical markers or neighborhood events. Furthermore, the exhibit could connect the local immigration history with the push-pull factors that drove immigration, especially if themes emerge that connect the history of immigrants across time, including new immigrant students.

Online or virtual tour and exhibit. Another way to reach a broad audience is the development of an online exhibit or virtual tour. Platforms such as Google Earth could be used to develop a map of the neighborhood with images and stories related to its immigrant past and present. This kind of site helps to connect the geography to the people who have lived there over time and also helps visitors to think about how the physical place has changed over generations. Another possible option is to develop e-books or other kinds of online sites that can combine images, audio, or even video interviews or archival film to tell the stories that were collected in the research. This kind of virtual exhibit could also be used to raise awareness of contemporary immigration and related issues - and could be used to link visitors to more information or ways to engage civically in these matters.

Augmented reality tour or game. Finally, using the model of the Greenbush example, students could construct a virtual tour or game-based experience for those interested in a neighborhood's immigrant past. A platform like ARIS or TaleBlazer can be used to construct a narrative-driven, place-based game that asks visitors to examine the history of place and the people who lived there as they explore the present day site. Other open source platforms, such as MIT's Locast, ${ }^{9}$ allow users to record and upload video, audio, and images from locations that can be accessed and viewed both on location and via a map interface online. This kind of platform allows producers and videos to explore the relationship between the socio-cultural history of immigrants and places. 
These types of augmented reality virtual tours or game experiences can be designed as a narrative to chronicle the experiences of a particular person, event, or group, or can be used to engage visitors in a particular inquiry question or scavenger hunt to explore these histories (e.g., Klopfer 2011; Squire 2010). Using augmented reality platforms and mobile technologies allows for the incorporation of artifacts, including images, audio, and text, related to the location that will allow visitors to engage with the voices and experiences of immigrants who stood in those same places decades or even centuries ago. And in the example of Locast, they could be used to record the experiences of present-day immigrants across the city. These contemporary experiences could be overlaid with those of immigrants from the past, to help reduce tensions related to immigration and provide for more empathetic understandings across a city or region's population.

These four examples of how students' work could be presented from a museum perspective are just a starting point. There are, of course, many other types of exhibit formats and environments that could be used to help visitors engage in the voices of local immigrants and the history of immigration - a history that has often been marginalized or told as part of a dominant historical narrative. However, what we have tried to do is provide some models for how students, as part of a museum education program, could explore these important histories from the perspective of a museum professional and engage authentic audiences, especially family and local community members, in what they have discovered in stimulating and interactive ways.

\section{Conclusion}

In this article, we have presented a model for using the work of museum professionals and the many resources and assets in museum education programs to engage young people in authentic historical inquiry. Grounded in the theory of situated learning, where learning takes place collaboratively between learners, experts, and tools such as archives and designed experiences in exhibits or historic sites, this authentic inquiry model is focused on a timely and important question regardless of location. To answer these questions, students must consider other topics of historical inquiry such as: Why have people historically immigrated, migrated, or emigrated? What have been the historical push and pull factors that cause these migration problems? What are the issues or tensions that have emerged as a result? And how can we engage the community in these stories to contribute to the civic and common good? These are important questions that should be part of a school history curriculum, but often are left out, especially where the local history is concerned, and therefore make a perfect complement to a museum education program to engage a local community in its own history through the study of material culture, archival materials, and the voices of those who have lived there.

Received: 11 October 2014

Finally Approved: 6 March 2015

\section{Notes}

1 According to Banks \& Banks (2009: 237), a contributions approach to multiculturalism, which is sometimes called a heroes and holidays approach, emphasizes important figures and events from historically marginalized groups without integrating them into the main national or historical narrative.

2 Joseph, B., (2013), "Using ARIS to Figure out "mobile locative embodied narrative-centric" games: An Interview with David Gagnon, ARIS, and Jennifer Sly, Minnesota Historical Society', http://www.mooshme.org/2013/09/

3 ARIS, http://arisgames.org; FreshAir, http://www.playfreshair.com; Aurasma, http://www. aurasma.com; TaleBlazer, http://taleblazer.org.

4 For more information on the MN History Center's use of ARIS, see http://education.mnhs. org/playthepast. 
5 Greenbush Game: http://www.regardingjohn.com/blog/ar-game-for-greenbush/

6 Lower East Side Tenement Museum, Accessed online April 14, 2013: http://www.tenement. org.

7 Minnesota Historical Society, Open House: If These Walls Could Talk, Minnesota History Center, St Paul, MN, USA: http://www.mnhs.org/exhibits/openhouse/

8 The Minnesota Historical Society's Historian's Tool Shed site (http://www.mnhs.org/exhibits/ openhouse/toolshed.htm) has helpful steps and tips for conducting archival research on buildings, for conducting oral history research, and for doing family or genealogical research.

9 Open Locast, MIT, Accessed online: http://locast.mit.edu.

\section{References}

Banks, J. A. (2008), 'Diversity, group identity, and citizenship education in a global age', Educational Researcher, 37(3), 129-139.

Banks, J. \& Banks, C. A. M. (eds), (2009), Multicultural education: Issues and perspectives, Hoboken, NJ: John Wiley \& Sons.

Barton, K., \& Levstik, L., (2004), Teaching history for the common good, Mahwah, NJ: Lawrence Erlbaum Associates.

Brown, JS, Collins, A, Duguid, S., (1989), 'Situated cognition and the culture of learning', Educational Researcher, 18(1), 32-42.

Chaiklin, S, Lave, J. (1993), Understanding practice: perspectives on activity and context, New York: Cambridge University Press.

Conforti, J., (1996), 'Ghettos as tourism attractions', Annals of Tourism Research, 23(4), 830-842.

Ellis, R., (2002). 'Interpreting the whole house', in J, Donnelly (ed), Interpreting historic house museums, 61-80, New York: Alta Mira Press.

Falk, J., and Dierking, L., (2000), Learning from museums: Visitor experiences and the making of meaning, Walnut Creek, CA: AltaMira Press.

Gottlieb, O. (April 2014), Whetting Appetites for Modern Jewish History with Mobile Geolocative Augmented Reality Gaming, Presented at the American Educational Research Association Annual Meeting, Philadelphia, PA.

Hess, D., (2009), Controversy in the classroom: The democratic power of discussion, New York: Routledge.

Ho, L. C., \& Seow, T., (2013), 'Teaching geography through "Chinatowns”: Global connections and local spaces', Social Education, 77(1), 36-41.

Hooper-Greenhill, E., (2000), Museums and the interpretation of visual culture, New York, NY: Routledge.

Klopfer, E., (2008), Augmented learning: Research and design of mobile educational games, Cambridge, MA: MIT Press. 
Ladson-Billings, G., (2003a), 'New directions in multicultural education', in J. Banks and C. Banks (eds), Handbook of research on multicultural education, 50-65, Hoboken, NJ: Josey-Bass.

Ladson-Billings, G., (2003b), 'Lies my teacher still tells', in G. Ladson-Billings, (ed), Critical race perspectives on social studies: The profession, policies, and curriculum, 1-11, Charlotte, NC: Information Age Press.

Lenoir, Y., \& Laforest, M., (1986), 'Le musée, un apport didactique au milieu scolaire ... s'il facilite les apprentissages prescrits!', in G. Racette (ed), Musée et éducation: modèles didactiques d'utilisation des musées, 20-23, Montréal: Société des Musées Québécois.

Loewen, J., (1995), Lies my teacher told me: Everything your high school history textbook got wrong, New York: New Press.

Marcus, A. S., Levine, T. H., \& Grenier, R. S., (2012), 'How secondary history teachers use and think about museums: Current practices and untapped promise for promoting historical understanding', Theory \& Research in Social Education, 40(1), 66-97.

Marcus, A., Stoddard, J., and Woodward, W., (2011), Teaching history with museums: Strategies for K-12 social studies, New York: Routledge.

Mathews, J., \& Squire, K., (2009), 'Augmented Reality gaming and game design as a new literacy practice' in Tyner, K. (ed), Media literacy: New agendas in communication, 209-232. New York: Taylor \& Francis.

Nespor, J., (2000), 'School field trips and the curriculum of public spaces', Journal of Curriculum Studies, 32 (1), 25-43.

Newmann, F. M., (1991), 'Classroom thoughtfulness and students' higher order thinking: Common indicators and diverse social studies courses', Theory and Research in Social Education, 19(4), 409-431.

Reid, D. A. (DATE), 'Making Gender Matter: Interpreting Male and Female Roles in Historic House Museums', in J, Donnelly (ed), Interpreting historic house museums, 81-110, New York: Alta Mira Press.

Rosenzweig, R., (2000), 'How Americans use and think about the past', in P. Stearns, P. Seixas, \& S. Wineburg (eds), Knowing, teaching, and learning history, 262-283, New York, NY: New York University Press.

Sexias, P., (1996), 'Conceptualizing the growth of historical understanding', in D. Olson and N. Torrance (eds), Handbook of education \& human development, 765-784, Cambridge, MA: Blackwell Publishers.

Shaffer, D., \& Resnick, M., (1999), “Thick” authenticity: New media and authentic learning', Journal of Interactive Learning Research, 10(2), 195-215.

Steinberg, A., (2012), 'What we talk about when we talk about food: Using food to teach history at the Tenement Museum', The Public Historian, 34(2): 79-89.

Squire, K., (2006), 'From content to context: Videogames as designed experience', Educational researcher, 35(8), 19-29.

Squire, K., (2010). 'From information to experience: place-based augmented reality games as a model for learning in a globally networked society', Teachers College Record, 112(10): 2565-2602. 
Squire, K., Jan, M., Mathews, J., Wagler, M., Martin, J., DeVane, B., \& Holden, C. (2007). 'Wherever you go, there you are: place-based augmented reality games for learning.' In Shelton, B. E., \& Wiley, D. (eds). The educational design and use of simulation computer games, 265-296. Rotterdam, The Netherlands: Sense Publishers.

Till, K., (2003), 'Places of memory', A companion to political geography, Malden, MA: Blackwell Publishers.

Trofanenko, B., (2006), 'Displayed objects, indigenous identities, and public pedagogy', Anthropology \& Education Quarterly, 37(4), 309-327.

VanSledright, B., (2011), The challenge of rethinking history education, New York: Routledge.

Wertsch, J., (1998), Mind as action. New York: Oxford University Press.

Wineburg, S., (2001), Historical thinking and other unnatural acts: Charting the future of teaching the past, Philadelphia, PA: Temple University Press.

\author{
Authors \\ *Jeremy Stoddard, College of William \& Mary (Virginia, USA)* \\ ${ }^{* *}$ Alan Marcus, University of Connecticut (Connecticut, USA) \\ ${ }^{* * *}$ Kurt Squire, University of Wisconsin - Madison (Wisconsin, USA) \\ **** John Martin, University of Wisconsin - Madison (Wisconsin, USA)
}

*Jeremy Stoddard is the Spears Distinguished Associate Professor of Education at the College of William \& Mary. He is a former middle school teacher and curriculum and technology professional development specialist whose research focuses on the role of media in teaching history and democratic education. In addition to over 30 articles and book chapters, he recently co-authored Teaching History with Film (2010) and Teaching History with Museums (Routledge, 2012).

Jeremy Stoddard

College of William \& Mary School of Education

PO Box 8795

Williamsburg, VA 23187 USA

Email: jdstod@wm.edu

Phone: 757-221-2348

${ }^{* *}$ Alan Marcus is an Associate Professor in the Department of Curriculum \& Instruction at the Neag School of Education, University of Connecticut. His research and teaching focus on social studies education and teacher education with an emphasis on the benefits and dilemmas of film and history museums as pedagogical tools in the history classroom. He recently co-authored Teaching History with Museums: Strategies for K-12 Social Studies (Routledge, 2012) and Teaching History with Film: Strategies for Secondary Social Studies (Routledge, 2010). Alan collaborates with museum educators across the United States and is the past president of the Connecticut Council for the Social Studies.

Alan Marcus

University of Connecticut (Connecticut, USA)

Associate Professor

alan.marcus@uconn.edu

Phone: 8604860281

Gentry 424

Unit 3033

249 Glenbrook Road

Storrs, CT 06269 
${ }^{* \star *}$ Kurt Squire is an associate professor at the University of Wisconsin-Madison in the Educational Communications and Technology division of Curriculum and Instruction and Associate Director for Educational Research and Development at the Wisconsin Institutes for Discovery. Squire's research investigates the design of game-based learning environments from a socio-cultural perspective, and he is the author of over 75 scholarly works. Recently Squire received an NSF CAREER grant to study scientific citizenship through playing Citizen Science, a role-playing game for scientific citizenship. With support from the MacArthur Foundation, Squire also produced ARIS, a mobile learning platform that is currently available on iTunes. Squire is a former Montessori and primary school teacher and was co-director of the Education Arcade. Squire is the vice president and a founding member of the Learning Games Network. Kurt Squire, University of Wisconsin - Madison (Wisconsin, USA)

544B Teacher Education Building

$225 \mathrm{~N}$ Mills St

Madison, WI 53706-1707

Office: $608 / 263-4672$

Fax: 608/263-9992

kurt.squire@gmail.com

****John Martin is a Learning Consultant with the Department of Information Technology at the University of Wisconsin-Madison. Over the years John has helped run a wilderness camp in Maine, worked with pre-service teachers and faculty in their use of technology, and led research into place based technologies in learning and augmented reality games. He earned his PhD in Educational Communications and Technology from UW-Madison.

John Martin, University of Wisconsin - Madison (Wisconsin, USA)

Sr. Teaching \& Learning Consultant

UW-Madison, Academic Technology

608-556-3061

john.martin@wisc.edu

William S Middleton Building

1305 Linden Dr

Madison, WI 53706 